\title{
Literature Review of Customer Service Value and Building Customer Value Model under the Internet Service Situation
}

\author{
Wang Xin ${ }^{1}$, Xu Ming ${ }^{1}$ \\ ${ }^{1}$ Glorious Sun School of Business and Management, Donghua University, P. R. China \\ Correspondence: Wang Xin, Glorious Sun School of Business and Management, Donghua University, Shanghai 200051, P. R. \\ China. Tel: 86-13564422721. Email: wangxinreport@126.com
}

Received: February 10, 2016

Accepted: February 23, 2016

Online Published: March 5, 2016

doi:10.5539/ibr.v9n4p118

URL: http://dx.doi.org/10.5539/ibr.v9n4p118

\begin{abstract}
The paper summarizes the study of customer service value at home and abroad, including the connotation of customer service value, analysis of the development history and research content, stage division. Through literature analysis, find out the new research hotspot. On the basis of previous research, the paper build customer value model under the situation of Internet service. In order to carry out further research in academic circles of our country to provide reference and reflection.
\end{abstract}

Keywords: service value, service value measurement, the Internet situation

\section{Introduction}

Customer value is composed of product value, service value, personnel value and image value, and the change of each value is influenced by the total value of customer value. Service value refers to enterprise provide customers with a variety of additional services with the sale of the product, including product introduction, delivery, installation, commissioning, maintenance, technical training, product assurance.

Service value is one of the important factors that constitute the total customer value. In the modern marketing practice, with the increase of the consumers income level and the change of their consumption concepts. When consumers buy products, they not only pay attention to the level of the value of the product itself, but also pays more attention to the added value of products. Especially in the quality and properties of similar products in roughly the same or similar, the enterprise which provide customers with value-added services more complete, more added value of the product, the actual benefits of the customer get is greater, than purchase the total value is greater; on the contrary, it is small. Therefore, in providing high quality products, enterprise should provide consumers with perfect service at the same time. This has become the new focus on the modern enterprise market competition.

At present, many literatures have discussed many aspects of customer service value, which have been developed in the breadth and depth of the study. In this paper, Integrated the main points of the literatures, from the service value of the research content and development stage, and other aspects of customer service value research conducted a comprehensive review of the existing research progress and deficiencies.

\section{Connotation of Customer Service Value}

For "value", Kotler Philip believes that value is a trinity of quality, service and price(QSP), and the value is the core concept of marketing ( Philip Kotler, 2011)

And in the research on the service value, the first is the American scholar Potter(1980) put forward the value chain model(Porter's Value-Chain Model), showed that the value chain of the enterprise includes the value brought by the service( Michael E. Porter., 1980). In the field of service science research, many scholars believe that the first service value theory related research content is Zeithaml, A. Zeithaml, V.A. Parasuraman and L.L. Berry (1985) and other scholars. In particular, the theory of service value of Zeithaml shows that is the most influential, and also relatively high degree of maturity. She pointed out: "the service value is generated in the customer service quality and the perceived service quality and its related pay (Zeithaml, 1988)". Support Zeithaml's theory is the theory of service quality gap model theory (Model of Service Quality GAPs). The model shows that the core of service quality gap theory is Gap1. The Gap1 is refers to service provider grasp of customer expectations and the actual customer of the gap between expected service and through the rest of the gap, explaining why customer satisfaction or dissatisfaction. 
Allee (2002) further divided customer service value into the following three categories of services: economic value, knowledge value and intangible value.

Spohrer J, Maglio P P, Bailey (2007) pointed out that the service is by service provider and customer co production, and work together to create a service value and it is an interaction process that meets the needs of both sides of supply and demand. Its core objectives through the services of both "collaborative production" and provide value for both sides of supply and demand.

Wang Zhongjie, Xu Xiaofei, Chu Dianhui, Chao Ma (2010) considered that the service value needs to be realized under the support of the specific service elements, and the value is transferred between the supply and demand sides. On the aspect of technology, service value can be through the service selection and service combination technology for service elements selected specific service component (Group) to achieve; and value realization degree is decided to the selected service component (Group) the quality parameters and between the value of a dependent relationship to each other.

\section{Main Research Contents of Customer Service Value}

\subsection{Key Words Analysis}

In order to understand the current international academic research on "customer service value", we use the WOS database as the foundation, to carry on the search and analysis, the retrieval theme is "service value customer", research orientation: MANAGEMENT、BUSINESS、COMPUTER SCIENCE INFORMATION SYSTEMS、ENGINEERING ELECTRICAL ELECTRONIC. Setting the time span: 1995-2015, the Index database includes: SCI-EXPANDED, SSCI, CPCI-S, CCR-EXPANDED, IC.

The number of indexed documents reaches 4411, the number of published literature as follows. From the number of citations visible, research on "customer service value" began around 1995, which in 2009 reached the study peak, then although the number of annual output of literature has declined, however, until today, the theme is still a hot research topic.

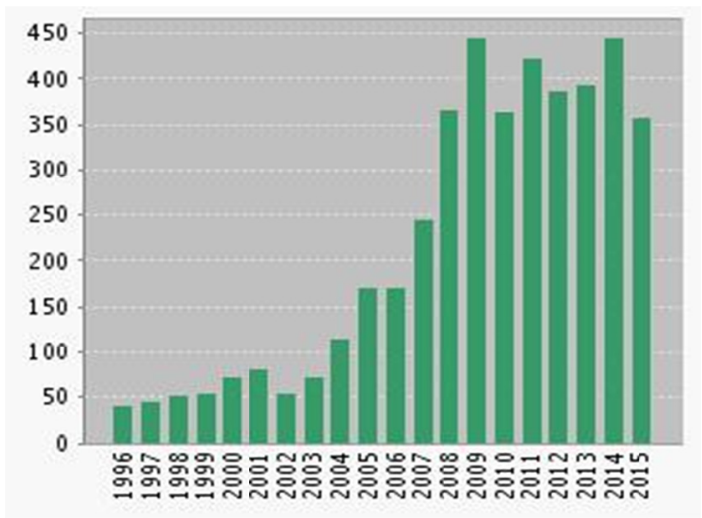

Figure 1. the number of published literature

In terms of key words, with the removal of some words similar to "service value customer", the frequency of the most frequent words summed up as follows:

Table1. Key words and citation impact

\begin{tabular}{lll}
\hline & Key words & Citation impact \\
\hline 1 & QUALITY & 513 \\
2 & SATISFACTION & 431 \\
3 & MODEL & 379 \\
4 & PERFORMANCE & 272 \\
5 & LOYALTY & 256 \\
6 & RELATIONSHIP & 237 \\
7 & CHAIN & 193 \\
8 & ONLINE & 159 \\
\hline
\end{tabular}

The key words can be further described in the following aspects: service quality, customer satisfaction, corporate performance, customer relationship, customer loyalty, metrics model, online sales, supply chain. 


\subsection{Literature Source Analysis and Development Stage Division}

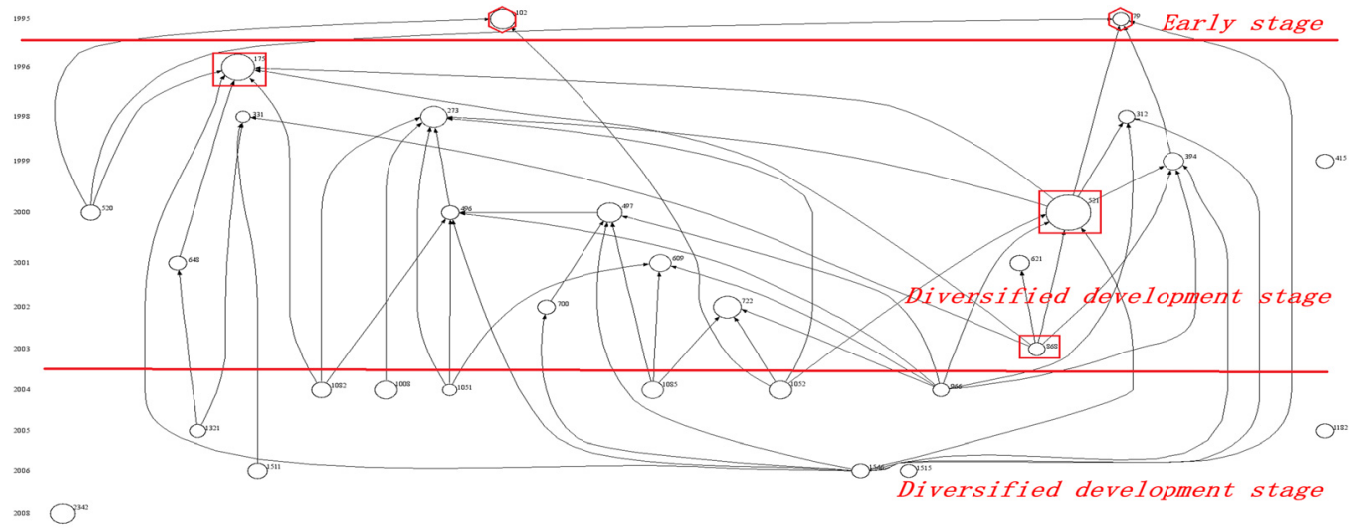

Figure 2. Service value citation relationship graph

In Figure 2, each circle represents a document, the larger circle represents the more times the literature is cited.

From the figure, we can see that in the subject under "customer service value", there are two source files. The one is OSTROM, A and IACOBUCCI, D(1995) published in JOURNAL OF MARKETING named " CONSUMER TRADE-OFFS AND THE EVALUATION OF SERVICES"( number 102); The other one is JONES, TO and SASSER, WE(1995) published in HARVARD BUSINESS REVIEW named "WHY SATISFIED CUSTOMERS DEFECT" ( number 79).

OSTROM, A and IACOBUCCI, D using the joint analysis method to study the choice of customer service, it is considered that the price, quality, friendliness of service personnel, and the degree of customization service are the main factors that affect the customer's choice of the service. JONES, TO and SASSER, WE pointed out that listen to customer demand is very important to improve customer satisfaction. When an error occurs in, the apology to the customer can also improve customer satisfaction.

Through analysing the relevant literature of Figure 2, we can sort out the development context and main research contents of customer service value research. For example: the source file (number 79) and another one numbered 273 are cited by "Assessing the effects of quality, value, and customer satisfaction on consumer behavioral intentions in service environments" (number 521) written by Cronin JJ ,Brady MK and Hult GTM.

Numbered 79 using conjoint analysis to examine subjects' utilities for service alternatives that differ in terms of price, level of quality, friendliness of the service personnel, and the degree of customization of the service., finally draw the conclusion: The results indicate that ail service attributes are important to consumers and that their importance varies with the mediating factors.

Bolton RN published an article in 1998 (no. 273) built a dynamic model to study the relationship between duration of the customers and the service providers.

The article number 521 is the most frequently cited article in the literature on the study of customer service value. On the basis of the above two documents, this paper uses SEM method to study the influence path of service quality, service value, satisfaction and behavior intention on the five variables.

On the basis of the number 521, the number 868 used a conceptual model of customer perceived value in the context of e-commerce. The model includes the content of the customer's online shopping experience, perceived commodity value, perceived risk of the goods and the price of goods.

According to the above analysis, we can get the main development phase of customer service value research in Figure 1:

1. Early stage; from the beginning of 1996, the preliminary study of the value of customer service related papers often use joint analysis method in quantitative analysis.

2. Development stage; development stage inherited the early stages of research results, and based on the development and research methods mainly to quantitative analysis, often use the structural equation to construct data models to verify the expectations hypothesis.

3. Diversified development stage; Multivariate development stage was under the background of the rapid development of Internet. The study of "customer service value" was not just confined to the entity in the service sector, began to expand to Internet related services, in B2B, B2C, C2C context, the values of customer service of related content. The 
integrated use of various quantitative analysis methods to explore the research topic.

\section{Customer Service Value Model under the Internet Situation}

Internet consumption, is a process that use the internet as a tool to achieve human own needs. The network not only provides instant consumer content, but also provides a range of services to "function".

On the basis of ACSI Fornell model and Joseph's competing models, this paper introduces the Internet scene model, constructs the customer service value model in the Internet context, as shown in the following figure.

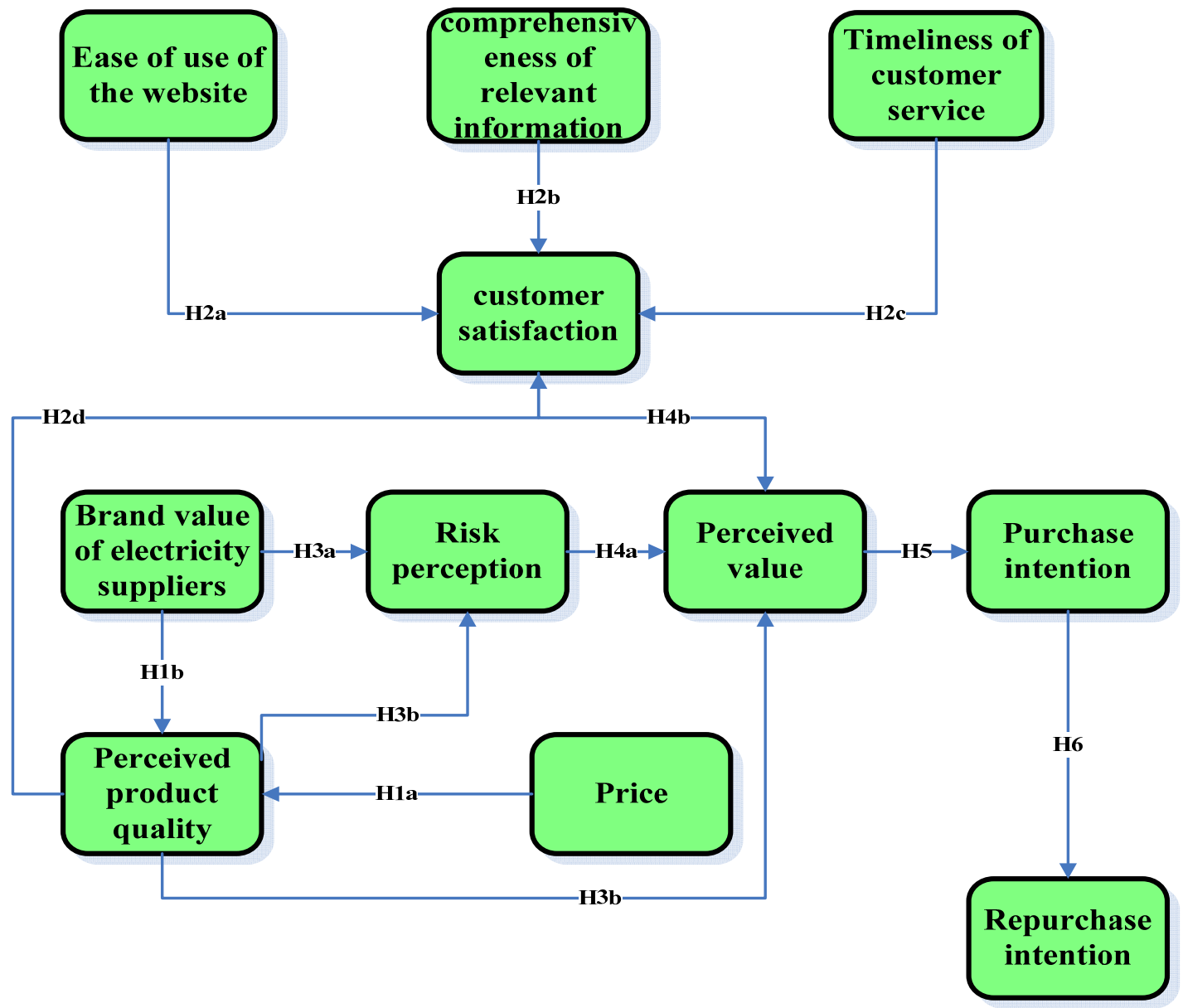

Figure 3. Customer service value model in the Internet Context

Hypothesis 1: customer initial perception from commodity prices and electricity suppliers brand of product quality.

H1a: product price has a significant impact on the perceived quality of the product;

H1b: brand value of electricity suppliers have a significant impact on the perceived quality of the product;

Hypothesis 2: in the context of the Internet, the biggest feature of the network consumption is the effect of increasing, consumption and production. That is to say, consumers should first put into the network resources and time resources, and on this basis "production" to satisfy the desire of consumer goods, in order to achieve the expected consumer utility, so network consumption is actually a "production - consumption of composite process.

So, if the electricity suppliers to reduce the consumption of this investment in the production of capital, that is, the network of consumer spending and time resources, which is beneficial to enhance customer satisfaction, strengthen customer purchase intentions. So the design of the site of the relevant attributes of the impact of customer satisfaction.

H2a: website has a significant impact on customer satisfaction;

$\mathrm{H} 2 \mathrm{~b}$ : related information has a significant impact on customer satisfaction;

$\mathrm{H} 2 \mathrm{c}$ : timeliness of customer service has a significant impact on customer satisfaction;

H2d: customer perceived product quality has a significant impact on customer satisfaction;

Hypothesis 3: because the network shopping behavior is different from the traditional shopping behavior, there is the 
risk of adverse selection and information asymmetry in the shopping process.

H3a: the brand value of electricity suppliers have a significant impact on customer risk perception;

H3b: customer perceived product quality has a significant impact on risk perception;

Hypothesis 4: the impact of customer satisfaction and perceived risk on perceived value

H4a: customer perceived value has a significant impact on perceived value;

$\mathrm{H} 4 \mathrm{~b}$ : customer satisfaction has a significant impact on perceived value;

Hypothesis 5: the influence of perceived value on purchase intention

H5: customer perceived value has a significant impact on customer purchase intention;

Hypothesis 6: for customers, many of the purchase behavior is not a one-time, so it is assumed that the purchase behavior has an impact on the next purchase behavior.

H6: customer's purchase intention has a significant impact on customer's repurchase intention;

In conclusion, due to the network consumption is under the Internet environment, this is different from the traditional consumer behavior, is a complex process of "production - consumption". In the research of customer service value, the traditional research contents and methods have been developed. Therefore, in the future research, the relevant research of customer service value under the Internet situation is expected to be more attention, or will become a new research hotspot.

\section{Reference}

Allee, V. A. (2002). Value network approach for modeling and measuring intangibles[J]. Transparent Enterprise, Madrid. http://www.vernaallee.com

Bolton, R. N. (1998). A dynamic model of the duration of the customer's relationship with a continuous service provider: The role of satisfaction. Marketing science, 17(1), 45-65.

Chen, Z., \& Dubinsky, A. J. (2003). A conceptual model of perceived customer value in e-commerce: A preliminary investigation . Psychology \& Marketing, 20(4), 323-347.

Cronin, J. J., Brady, M. K., \& Hult, G. T. M. (2000). Assessing the effects of quality, value, and customer satisfaction on consumer behavioral intentions in service environments. Journal of Retailing, 76(2), 193-218. http://dx.doi.org/10.1016/S0022-4359(00)00028-2

Fornell, C., \& Mark, J. (1996). The American Customer Satisfaction Index: Nature, Purpose, and Findings. Journal of Marketing, 60, 7-18. http://dx.doi.org/10.2307/1251898

Jones, O. T. (1995). Why Satisfied Customer Defect. Harvard Business Review, 73(11-12), 88-99.

Michael E. P. (1985). Competitive Advantage Creating and Sustaining Superior Performance. New York: The MaCmillan Press.

Ostrom, A., \& Iacobucci, D. (1995). Consumer trade-offs and the evaluation of services. Journal of Marketing, 59, 17-28. http://dx.doi.org/10.2307/1252011

Parasuraman, A., Zeithaml, V. A., \& Berry, L. L. (1985). A conceptual model of service quality and its implications for future research. Journal of Marketing, 49(4), 41-50. http://dx.doi.org/10.2307/1251430

Philip, K. (2011). Marketing Management (Thirteenth Edition), Tsinghua university press, 53-54.

Spohrer, J., Maglio, P. P., \& Bailey, J., et al. (2007). Steps toward a science of service systems[J]. Computer, 40(1), 71-77. http://dx.doi.org/10.1109/MC.2007.33

Wang, Z. J., Xu, X. F., Chu, D. H, \& Chao, M. A. (2010).Value-Driven Approach for the Determination of Global Optimization Objective of Service Composition[C]//Services Computing (SCC), 2010 IEEE International Conference on. IEEE, 2010: 210-217.

\section{Copyrights}

Copyright for this article is retained by the author(s), with first publication rights granted to the journal.

This is an open-access article distributed under the terms and conditions of the Creative Commons Attribution license (http://creativecommons.org/licenses/by/3.0/). 